\title{
SITUACIÓN FISCAL DEL DEPARTAMENTO DE SANTANDER EN EL MARCO DEL PROCESO DE DESCENTRALIZACIÓN FISCAL EN COLOMBIA, 2000-2013
}

The financial situation of the department of Santander in the context of the tax decentralization in Colombia, 2000-2013

\section{Jorge Enrique Asela - Molina}

Economista por la Universidad Industrial de Santander. Bucaramanga-Colombia, jorgeasela@hotmail.com

\author{
Cómo citar / How to cite \\ Asela-Molina, J.E. (2016). Descripción de la situación fiscal del departamento de Santander en el marco del \\ proceso de descentralización fiscal de Colombia, 2000-2013. Revista CEA, 2(3), 73-86.
}

Recibido: 9 de febrero de 2015

Aceptado: 12 de septiembre 2015

\section{Resumen}

Este documento presenta el proceso de descentralización en Colombia desde su plano fiscal, a través del marco normativo que lo comprende y cómo es su relación con las finanzas públicas del departamento de Santander, esto mediante la identificación de la situación fiscal del departamento en el periodo 2000-2013. La reflexión se genera tomando como base los ingresos y gastos presupuestales del departamento y los indicadores de esfuerzo fiscal, dependencia intergubernamental y autonomía fiscal departamental, indicadores planteados por el Departamento Nacional de Planeación (DNP), que dejan ver la falta de autonomía financiera y el grado de dependencia de los recursos provenientes del Sistema General de Participación (SGP) y de regalías.

Palabras clave: descentralización fiscal, ingresos, gastos, indicadores de esfuerzo fiscal.

\begin{abstract}
This document presents the decentralization process in Colombia from the fiscal perspective and by means of its regulatory framework as well as the relationship it has with the public finances of the department of Santander. All of this is done by describing the taxes situation of the department in the term 2000- 2013. The reflection is created based on the revenues and planed expenses of the department and the indicators of fiscal effort, the intergovernmental office and the department fiscal autonomy, criteria set by the National Planning Department (DNP), which reveal the lack of financial autonomy and the extent of the dependency of the resources coming from the General System of Participation (SGP) and the royalties.
\end{abstract}

Keywords: fiscal decentralization, revenues, costs, indicators of fiscal effort. 


\section{INTRODUCCIÓN}

El modelo de descentralización en Colombia, como estructura de organización del Estado, empezó a tomar relevancia en la década de 1980, producto de las constantes crisis que a finales de la misma época el país vivió en los ámbitos económico, político y social. Para los años noventa, la promulgación de una nueva Constitución (1991) permitió que el modelo de descentralización, como mecanismo de conformación del Estado, se afianzara, generando para los entes subnacionales la posibilidad de contar con autonomía a nivel político, administrativo y fiscal.

Tomando como punto de partida el concepto de descentralización, el presente documento busca mostrar la evolución del proceso de descentralización fiscal en Colombia desde su marco normativo, con el objetivo de dilucidar la realidad fiscal del departamento de Santander en el periodo comprendido entre los años 2000 a 2013, asimismo, reflexionar sobre el comportamiento de los ingresos y gastos presupuestales del departamento e indicadores de dependencia intergubernamental, esfuerzo fiscal y autonomía fiscal departamental, planteados por el Departamento Nacional de Planeación (DNP) de Colombia.

La revisión de la situación fiscal del departamento de Santander, a la luz del comportamiento de sus ingresos y gastos presupuestales, permite conocer el grado de autonomía, dependencia y esfuerzo que en materia fiscal realizó el departamento durante el periodo de estudio.

El artículo presenta, en su primera parte, una descripción teórica del concepto de descentralización; en segundo lugar, aborda el marco normativo de la descentralización fiscal en Colombia, haciendo énfasis sobre las leyes y normas que formalizan las rentas del nivel intermedio de gobierno; finalmente, presenta un análisis del comportamiento de los ingresos y gastos presupuestales, además de algunos indicadores de desempeño fiscal planteados por el DNP.

\section{DESCENTRALIZACIÓN}

La descentralización se define como un «proceso de reforma del Estado, compuesto por un conjunto de políticas públicas que transfieren responsabilidades y recursos desde una autoridad mayor a niveles menores de gobierno, en el contexto de un específico tipo de Estado» (Falleti, 2005, p. 328).

La descentralización es un modelo de estructuración del Estado, en el cual la administración pública se divide entre los diferentes niveles de Gobierno (central, regional, local), el cual, de acuerdo con Finot (2002), cuenta como principales objetivos: «i) aumentar la eficiencia de la administración pública, ii) mayor equidad entre los territorios, y iii) propiciar una participación constructiva entre la ciudadanía y sus gobernantes» (p. 140). La obtención de dichos objetivos se fundamenta en la entrega por parte del Gobierno central a los Gobiernos subnacionales de autonomía en materia política, administrativa y fiscal.

La descentralización administrativa se define como «la transferencia de funciones, recursos y capacidades de decisión del Gobierno nacional a los entes territoriales» (Penning, 2003, p. 126), es decir, la decisión e implementación de políticas y recursos sobre las territorialidades se genera dentro de los mismos Gobiernos subnacionales. Por otro lado, la descentralización política es entendida como el derecho autónomo de los pobladores de los Gobiernos locales a elegir sus propios gobernantes, alejándose de la designación como mecanismo de representación, esta ocurre cuando la forma en que se encuentran constituidos los gobiernos territoriales a nivel dirigencial se ve alterada por una reforma, misma que encuentra, en la elección popular y no en la designación, la forma idónea para la conformación de los cuerpos colegiados y gobernantes locales (Eaton, 2004). 
La descentralización fiscal es definida como «el conjunto de políticas diseñadas para aumentar los ingresos o autonomía fiscal de los Gobiernos subnacionales» (Falleti, 2005, p. 329) y se presenta «cuando las competencias fiscales (ingresos y gastos públicos) se desplazan del nivel superior o central hacia el inferior o subnacional» (Aghón y Krause-Junk, 1993, p. 8). La descentralización fiscal surge como la base para el fortalecimiento de los procesos a nivel administrativo y político que presentan los Gobiernos locales, dado que pretende desligar a los Gobiernos territoriales de la dependencia de los recursos del nivel central, a través de la autonomía en la generación de rentas e impuestos propios que permitan el cumplimiento de sus obligaciones, ya no con el Gobierno central, sino, con la población que se encuentra bajo su jurisdicción.

En síntesis, la descentralización es entendida como un modelo de conformación del Estado que rige la administración pública bajo principios de equidad y eficiencia, esto a través de la entrega, por parte del nivel superior de Gobierno a los entes subnacionales, de autonomía en los planos político, administrativo y fiscal.

\section{MARCO NORMATIVO DE LA DESCENTRALIZACIÓN FISCAL EN COLOMBIA (1960-2012)}

En Colombia, los primeros pasos en materia de descentralización en el plano fiscal se presentaron en el gobierno de Lleras Restrepo (1966-1970) con la Ley 33 de 1968, la cual promovió el fortalecimiento de los fiscos seccionales y municipales mediante la cesión, por parte del Gobierno central, de los impuestos sobre los premios de lotería, destilación e impuesto de venta de licores destilados de producción nacional y el impuesto de registro y anotación.

En ese mismo mandato, haciendo uso de las facultades establecidas por la Ley 65 de 1967, se establece mediante el Decreto 472 de 1968 la creación de una comisión de expertos (Misión Musgrave), que estudiaría y realizaría propuestas de fondo para reformar el sistema fiscal del país. Producto de esta misión se promulgó la Ley 46 de 1971, la cual dio origen a la creación del Situado Fiscal.

El Plan de Integración Nacional (PIN), propuesto por el gobierno de Julio César Turbay Ayala (1978-1982), plantea como uno de sus objetivos primordiales la búsqueda de una descentralización económica y mayor autonomía regional (Junguito y Rincón, 2004), por lo cual en este Gobierno se promulgan las Leyes 7 de 1981 y 14 de 1983, la primera con el fin de entregar una mayor autonomía fiscal a los departamentos, generando la posibilidad para los gobernadores, previa autorización de las asambleas departamentales, el adelanto de operación de crédito público. La segunda -Ley 14 de 1983-, con la reforma de la estructura impositiva de los departamentos y municipios, entre otras disposiciones, se implementó un cambio en la base y la tasa del impuesto de industria y comercio, e impuesto de consumo al licor y a los cigarrillos, se genera la cesión a los departamentos del recaudo sobre el impuesto al timbre de vehículos; además, se presenta la actualización de la base gravable del impuesto predial y se crea el impuesto de circulación y tránsito. Estas modificaciones a la estructura de impuestos de orden territorial serían conocidas como el estatuto de tributación nacional.

A mediados de la década de los ochenta, con la Ley 12 de 1986, se presenta una modificación al porcentaje que por concepto del impuesto al valor agregado (IVA) perciben los entes territoriales, además de la forma de asignación y disposición de los mencionados recursos. En 1987, con el Decreto 77, se establece el sistema de cofinanciación como mecanismo de inversión pública y con la Ley 44 de 1990 se estructura el impuesto predial unitario, permitiendo a los órganos colegiados de las territorialidades el establecimiento de tarifas.

Con la proclamación de la Constitución Política de 1991, se afianza el proceso de 
descentralización en el plano fiscal. La Constitución, en su Artículo 287, establece la participación por parte de los entes subnacionales de las rentas del Gobierno central, además de la posibilidad de generar alternativas que le permitan incrementar sus recursos. De igual manera, condiciona a la nación, dentro del Artículo 362, en actividades de apropiación de recursos que vía impuestos recauden los entes territoriales, salvo en caso de guerra exterior; del mismo modo prohíbe la utilización de sobretasas o excepciones de ley en los impuestos de orden local (Artículo 294).

Como complemento a los recursos que por esfuerzo propio recaudan los departamentos y municipios, la Constitución (Artículos 356 y 357) dispone la asignación de transferencias, esto vía Sistema General de Participación (SGP), antiguo situado fiscal, estableciendo la destinación y uso de los recursos en los sectores de salud, educación y saneamiento básico. En los Artículos 360 y 361 se establecen los temas correspondientes a regalías que serían reglamentados bajo la Ley 141 de 1994, creando el Fondo Nacional de Regalías (FNR) y la Comisión Nacional de Regalías, permitiendo a los entes subnacionales participar directamente de los recursos que por la explotación de recursos no renovables recibe el Gobierno central. Posteriormente, la Ley 141 de 1994 sería modificada por la Ley 1530 de 2012, eliminando el FNR y creando el Sistema General de Regalías (SGR).

Con las Leyes 358 de 1997, 549 de 1999, 550 de 1999 y 617 de 2000, entre otras disposiciones, se crea el Fondo Nacional de Pensiones de las Entidades Territoriales (FONPET), se dispone el cubrimiento de los gastos de funcionamiento vía ingresos producto del ejercicio tributario, se presentan alternativas para la restructuración del pasivo de los entes subnacionales, y modificando la Ley 136 de 1994 se clasifica a los departamentos y municipios en categorías, esto teniendo como base las variables población e ingresos corrientes de libre destinación (ICLD). (Ver tablas 1 y 2 ).

Tabla 1. Clasificación de los Departamentos por categorías

Table 1. Departments categorization

\begin{tabular}{|c|cc|cc|}
\hline Categoría & \multicolumn{2}{|c|}{ Habitantes entre } & \multicolumn{2}{c|}{ ICLD (smmlv) entre } \\
\hline Especial & $>$ & 2.000 .000 & $>$ & 600.000 \\
1 & 700.000 & 2.000 .000 & 170.000 & 600.000 \\
2 & 390.000 & 700.000 & 122.000 & 170.000 \\
3 & 100.000 & 390.000 & 60.000 & 122.000 \\
4 & $<$ & 100.000 & $<$ & 60.000 \\
\hline
\end{tabular}

Fuente: elaborada con información de la Ley 617 de 2000.

Tabla 2. Clasificación de los Municipios por categorías

Table 2. Categorization Towns

\begin{tabular}{|c|cc|cc|}
\hline Categoría & \multicolumn{2}{|c|}{ Habitantes entre } & \multicolumn{2}{c|}{ ICLD(smmlv) entre } \\
\hline Especial & $>$ & 500.001 & $>$ & 400.000 \\
1 & 500.000 & 100.001 & 100.000 & 400.000 \\
2 & 100.000 & 50.001 & 50.000 & 100.000 \\
3 & 50.000 & 30.001 & 30.000 & 50.000 \\
4 & 30.000 & 25.000 & 25.000 & 30.000 \\
5 & 20.000 & 15.000 & 15.000 & 25.000 \\
6 & $<$ & 10.000 & $<$ & 15.000 \\
\hline
\end{tabular}

Fuente: elaborada con información de la Ley 1551 de 2012. 
Con el fin de continuar fortaleciendo los ingresos de los territorios, se promulgan las Leyes 663 de 2000, 788 de 2002 y 863 de 2003, las cuales, entre otras disposiciones, crean el Gravamen a los Movimientos Financieros (GMF) -de orden nacional- y fortalecen el estatuto tributario.

En lo referente a los recursos que vía transferencia reciben los entes territoriales, se promulga la Ley 60 de 1993, la cual dispone las competencias de los diferentes niveles de Gobierno, además del porcentaje y destinación de los recursos del situado fiscal, con la Ley 715 de 2001 se crea el Sistema General de Participación (SGP) y se modifican el porcentaje de destinación de los sectores, esta sería posteriormente modificada por la Ley 1176 de 2007 (Ver tabla 3).
Como se evidencia, el proceso de descentralización fiscal en Colombia se ha orientado principalmente a tres aspectos: 1 ) Flujo creciente de recursos, el cual es visible con el aumento de las transferencias por parte del Gobierno central, incremento de la tributación territorial y la destinación de una mayor cantidad de recursos del Presupuesto General de la Nación (PGN) a los entes territoriales. 2) Sostenibilidad y responsabilidad fiscal, esto por medio del endeudamiento sostenible por parte de los departamentos y municipios, hacer viables los gastos de funcionamiento y la recuperación de la sostenibilidad fiscal. Finalmente, como tercer aspecto, está la medición y difusión del desempeño fiscal, el cual se realiza a través del aumento de la calificación del desempeño fiscal y la disponibilidad de información sobre el desempeño fiscal de las entidades territoriales para la comunidad en general (Carrillo, 2009).

Tabla 3. Asignación de Recursos Según Leyes 60 de 1993, 715 de 2001 y 1176 de 2007 Table 3. Allocation of Resources According to Law 60 of 1993, 715 of 2001 and 1176 of 2007

\begin{tabular}{|l|c|c|c|}
\hline \multicolumn{1}{|c|}{ Sectores } & Ley 60/1993 & Ley 715/2001 & Ley 1176/2007 \\
\hline Educación & $30 \%$ & $58,5 \%$ & $58,5 \%$ \\
Salud & $25 \%$ & $24,5 \%$ & $24,5 \%$ \\
Propósito General & - & $* 17 \%$ & $* 11,6 \%$ \\
Agua Potable y Saneamiento Básico & $20 \%$ & $41 \%$ & $5,4 \%$ \\
Deporte, Recreación y Cultura & $5 \%$ & $7 \%$ & $83 \%$ \\
Fonpet & - & $10 \%$ & \\
Libre Destinación & $20 \%$ & $42 \%$ & $17 \%$ \\
\hline
\end{tabular}

Fuente: Asela, J. (2014), p. 71. La asignación de recursos de la Ley 715 de 2001 para los sectores de agua potable y saneamiento básico, deporte recreación y cultura, Fonpet y libre destinación, son derivados del total de recursos de propósito general (*17\%); del mismo modo, la asignación de recursos en la Ley 1176 de 2007 para los sectores de deporte, recreación y cultura, Fonpet y libre destinación son derivados del total de los recursos de propósito general (*11,6\%) según disposición de Ley.

\section{Rentas departamentales}

Las rentas departamentales están constituidas por los recursos propios y las transferencias. Los recursos propios, según el DNP (2014), son todos aquellos ingresos corrientes que los entes territoriales generan por su actividad misional y potencial económico, o en palabras de Wiesner (2002), son los ingresos «derivados directamente de la base tributaria que está bajo jurisdicción autónoma de las autoridades municipales o regionales» (Wiesner, 2002, p. 5); 
son producto del ejercicio tributario presentado por el ente territorial a través de la cobranza de impuestos y su gestión pública. En cambio, las rentas por transferencias son entendidas como los recursos que un nivel de gobierno transfiere a otro con el fin de cumplir con las políticas planteadas desde el nivel de gobierno del que derivan. Para Wiesner, este mecanismo se constituye en la herramienta transmisora de la descentralización, dado principalmente a los tres objetivos que presenta: «i) igualar condiciones iniciales territoriales, ii) inducir cambios en las políticas territoriales, iii) capitalizar externalidades interjurisdiccionales» (2002, pp. 4-5).

Dentro de la estructura contable, estas rentas (recursos propios y transferencias) están divididas en dos rubros: ingresos corrientes e ingresos de capital. Los ingresos corrientes se encuentran separados en tributarios y no tributarios; entre los tributarios encontramos los ingresos producto del ejercicio tributario, como lo son los recursos provenientes del recaudo de los impuestos a la cerveza, licores, cigarrillo y tabaco, registro y anotación, vehículos y automotores, sobretasa a la gasolina $y$ otros. Los ingresos no tributarios son las transferencias corrientes y constituyen la base de la autofinanciación de los gobiernos seccionales.

En relación con los ingresos de capital, se encuentran divididos en transferencias, las cuales son los recursos que vía Sistema General de Participación (SGP) otorga el Gobierno central; las regalías, producto de la explotación de recursos no renovables y vía Sistema General de Regalías (SGR); la cofinanciación con otros niveles de Gobierno o sector privado; y por último, otros recursos, entre los que encontramos los crédito y las donaciones. Los ingresos de capital entran a complementar los recursos que a través del ejercicio tributario perciben los departamentos.

En síntesis, hacen parte de los tributos departamentales las rentas provenientes del nivel central como de sus entidades descentralizadas, por concepto de tasas, impuestos, contribuciones, monopolios, explotación de bienes, regalías, participaciones, sanciones pecuniarias y en general todos los ingresos que le correspondan para el cumplimiento de sus fines constitucionales $y$ legales.

\section{ANÁLISIS FISCAL DEL DEPARTAMENTO DE SANTANDER (2000-2013)}

Este análisis tiene como referencia la descripción de los ingresos y gastos presupuestales del departamento de Santander y algunos de los indicadores fiscales propuestos por el Departamento Nacional de Planeación DNP: Esfuerzo fiscal (Ingresos Tributarios/Ingresos Totales), Dependencia intergubernamental (Transferencias de la Nación/Ingresos Totales)(Regalías/Ingresos Totales) y Autonomía fiscal departamental (Gastos de funcionamiento/Ingresos Corrientes de libre destinación) en los años 2000 a 2013, elementos que permitirán una mejor lectura sobre el estado actual de la realidad fiscal en el departamento.

La evolución de las finanzas públicas del departamento de Santander, en términos reales (a precios de 2008), pasaron de ingresos de $\$ 382.248$ millones y gastos de $\$ 323.132$ millones en el año 2000, a ingresos y gastos de $\$ 982.557$ millones y $\$ 979.618$ millones de pesos, respectivamente, en el año 2013 (ver Fig. 1), incremento justificado en el caso de los ingresos por un constante crecimiento en las transferencias de la nación y el mayor recaudo de rentas propias. Por el lado del gasto, la implementación de políticas sociales en los sectores de educación, salud, saneamiento básico, planes en desarrollo de infraestructura y el creciente aumento en el gasto de funcionamiento del ente territorial, son los rubros que principalmente componen el crecimiento del gasto en la administración departamental. 
Tabla 4. Indicadores esfuerzo fiscal, dependencia intergubernamental, autonomía fiscal, departamento de Santander 2000-2013

Table 4. Indicators fiscal effort, intergovernmental dependence and department fiscal autonomy, departament of Santander 2000-2013

\begin{tabular}{|ccccc|}
\hline \multicolumn{4}{c}{ Departamento de Santander } \\
\cline { 1 - 3 } Año & $\begin{array}{c}\text { Esfuerzo } \\
\text { fiscal }\end{array}$ & \multicolumn{2}{c|}{ Dependencia } \\
\cline { 3 - 4 } & intergubernamental & Autonomía \\
fegalías & Nación & \\
\hline 2000 & 0,38 & 0,22 & 0,30 & 0,70 \\
2001 & 0,40 & 0,21 & 0,30 & 0,65 \\
2002 & 0,23 & 0,07 & 0,68 & 0,72 \\
2003 & 0,30 & 0,09 & 0,54 & 0,76 \\
2004 & 0,32 & 0,11 & 0,46 & 0,69 \\
2005 & 0,32 & 0,09 & 0,48 & 0,54 \\
2006 & 0,29 & 0,17 & 0,44 & 0,41 \\
2007 & 0,31 & 0,13 & 0,41 & 0,47 \\
2008 & 0,26 & 0,19 & 0,35 & 0,56 \\
2009 & 0,32 & 0,14 & 0,36 & 0,51 \\
2010 & 0,31 & 0,15 & 0,31 & 0,60 \\
2011 & 0,33 & 0,20 & 0,42 & 0,63 \\
2012 & 0,34 & 0,14 & 0,38 & 0,84 \\
2013 & 0,36 & 0,11 & 0,39 & 0,56 \\
\hline
\end{tabular}

Fuente: elaborada con datos del DNP.

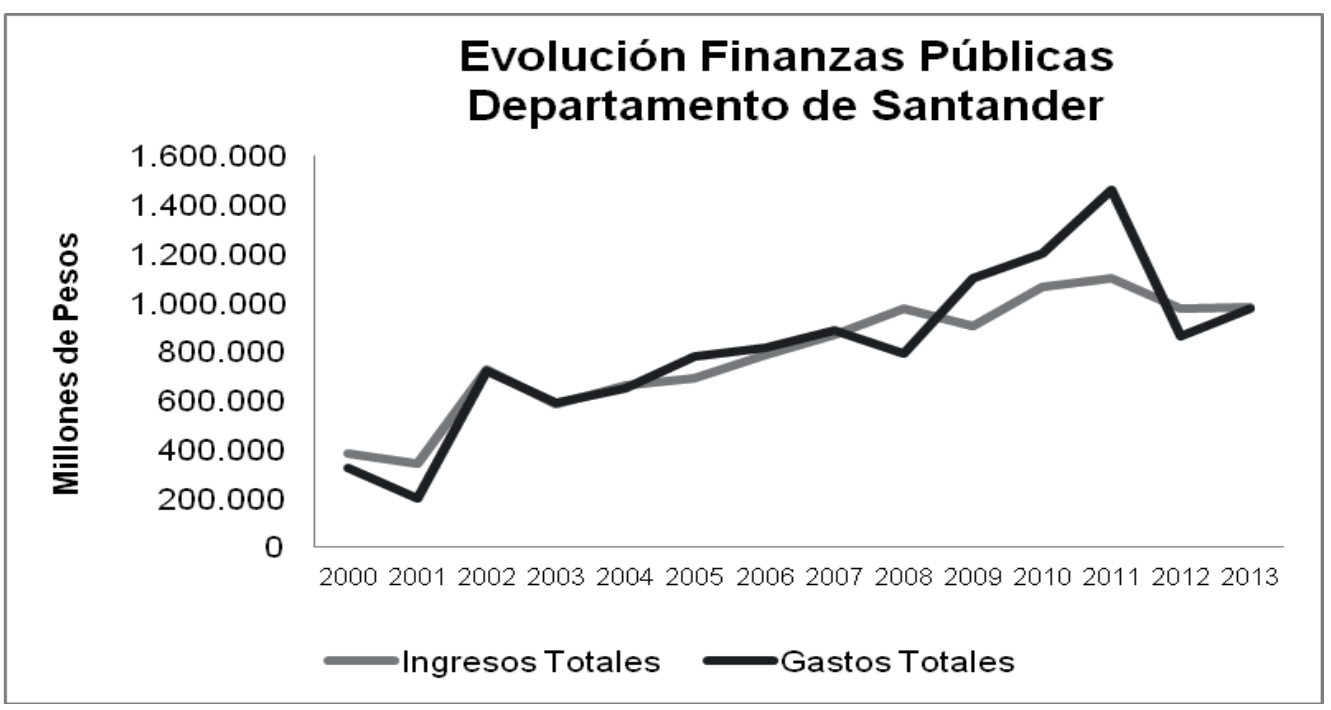

Figura 1. Evolución Finanzas Públicas Departamento de Santander Figure 1. Evolution Finances Public of the Department of Santander Fuente: Elaborada con datos del DNP. 
La contraposición de los ingresos y gastos totales del departamento, durante el periodo de estudio, evidencia un comportamiento parejo de estabilidad fiscal hasta el año 2004, en donde se presentan superávits importantes en los años 2000 (de $\$ 59.110$ millones de pesos) y 2001 (con $\$ 139.839$ millones de pesos) debido a la caída en los gastos en sectores sociales y al posterior crecimiento de los recursos por transferencias de la nación. Para los años posteriores, el comportamiento del ejercicio fiscal del departamento presenta déficits durante los años 2005, 2006, 2007, en donde la inversión en la formación bruta de capital fijo (FBCF) presenta importantes incrementos, al pasar en 2005 de \$174.008 millones de pesos a 2007 a $\$ 430.728$ millones de pesos, lo que explica el aumento del gasto en esos años; en el año 2008 se presenta una recuperación -superávit de $\$ 180.743$ millones de pesos-, en donde nuevamente la disminución en la inversión social y la FBCF sumado a un incremento en los recursos percibidos por regalías (\$67.044 millones de pesos más respecto al año anterior) explican el mencionado comportamiento. Ahora bien, en los años 2009 al 2011 continua la tendencia negativa, déficits de \$192.741, \$137.242 y $\$ 358.424$ millones de pesos, presentando una recuperación en los dos últimos años del periodo de estudio, con superávits de $\$ 116.045$ y \$2.939 millones de pesos respectivamente (ver Fig. 1).

\section{Los ingresos del departamento de Santander}

La evolución de los ingresos totales del departamento de Santander se presenta favorable durante casi todo el periodo de análisis, mostrando incremento en los mismos durante la mayoría de los años tomados para el estudio (ver Fig. 2), siendo del 2004-2011 donde la tendencia se da con mayor fuerza, presentando las siguientes variaciones respecto al año anterior: 2004 de 13\%, 2005 de 4,1\%, 2006 de 13,8\%, 2007 de 10,5\%, 2008 de 12\%, 2009 de $-7 \%$, 2010 de 17,6\% y 2011 de 3,3\%, lo cual evidencia un ejercicio tributario favorable y un incremento sustancial durante el periodo de los ingresos de capital; en los años 2012 y 2013 se genera una caída en los ingresos percibidos, dada la disminución de los recursos por transferencias de la nación y los recursos por regalías (ver Tabla 5).

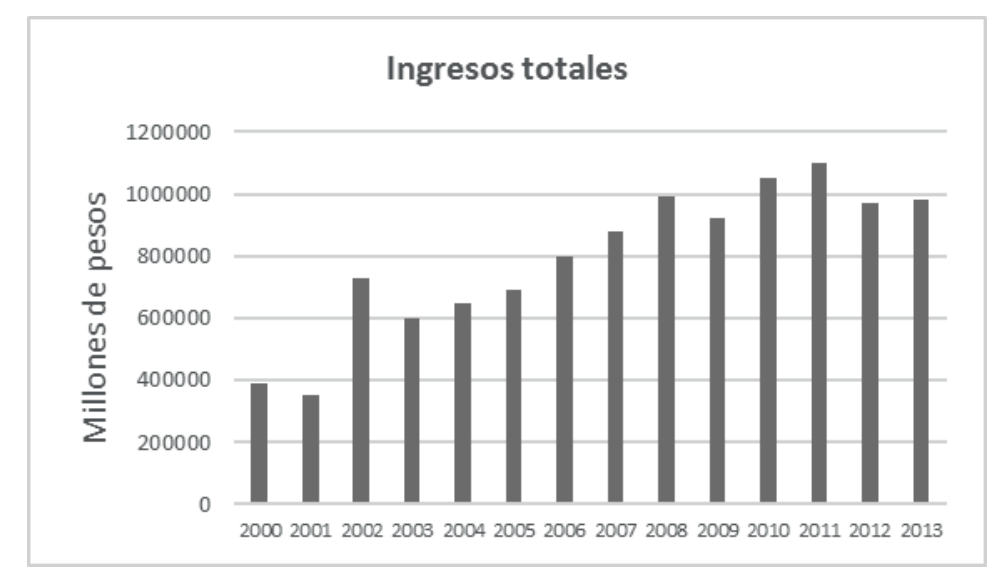

Figura 2. Ingresos Totales del Departa4mento de Santander 2000-2013

Figure 2. Totals the Department of Santander 2000-2013

Fuente: elaborada por el autor con datos del DNP.

Los ingresos totales promedio del departamento de Santander, durante el periodo de estudio, se encuentran compuestos en un $35,9 \%$ por los ingresos corrientes, de los cuales el 31,7\% corresponde a los ingresos tributarios, es decir, al recaudo de las rentas vía tarifa y tasa impositiva proveniente de impuestos como: la cerveza, licor, cigarrillos, sobretasa a la gasolina, 
vehículos y automotores y otros. Los ingresos no tributarios aportan el 3,2\%, y el $1,1 \%$ corresponde a las transferencias corrientes; los ingresos de capital representan el $64,1 \%$ de los ingresos totales del departamento, de los cuales las transferencias vía Sistema General de la Nación (SGN) aportan el 43,4\%, las regalías equivalen un $14,6 \%$ y otros ingresos el restante 6,1\% de los ingresos de capital (ver Tabla 5).

Tabla 5. Composición porcentual de los ingresos del departamento de Santander 2000-2013

Table 5. Percent composition of the revenues of the department Santander 2000-2013

\begin{tabular}{lrrrrrrrrrrrrrrrr}
\hline & 2000 & 2001 & 2002 & 2003 & 2004 & 2005 & 2006 & 2007 & 2008 & 2009 & 2010 & 2011 & 2012 & 2013 & X \\
\hline Total & 100 & 100 & 100 & 100 & 100 & 100 & 100 & 100 & 100 & 100 & 100 & 100 & 100 & 100 & 100 \\
Corrientes & 44,6 & 46,2 & 23,0 & 32,1 & 38,5 & 40,9 & 31,3 & 34,3 & 28,2 & 38,3 & 35,4 & 35,9 & 38,0 & 39,2 & 36,1 \\
Tributarios & 38,5 & 40,1 & 22,8 & 30,0 & 32,0 & 32,4 & 28,9 & 31,1 & 25,6 & 32,2 & 31,0 & 32,9 & 34,0 & 36,0 & 32,0 \\
No Tributarios & 6,1 & 6,1 & 0,2 & 1,4 & 3,1 & 3,1 & 2,3 & 3,2 & 2,3 & 3,7 & 3,0 & 3,0 & 3,6 & 3,2 & 3,2 \\
& & & & & & & & & & & & & & & \\
Transferencias Corrientes & 0 & 0 & 0 & 0,7 & 3,4 & 5,4 & 0 & 0 & 0,4 & 2,5 & 1,5 & 0 & 0,3 & 0,0 & 1,0 \\
De Capital & 55,4 & 53,8 & 77,0 & 67,9 & 61,5 & 59,1 & 68,7 & 65,7 & 71,8 & 61,7 & 64,6 & 64,1 & 62,0 & 60,8 & 63,9 \\
Transferencias & 30,0 & 29,5 & 67,7 & 54,0 & 46,3 & 47,9 & 47,9 & 44,4 & 38,9 & 35,8 & 42,0 & 42,3 & 37,7 & 38,5 & 43,1 \\
Regalías & 21,7 & 20,7 & 6,9 & 9,1 & 10,6 & 8,9 & 16,5 & 13,4 & 18,8 & 14,5 & 15,5 & 19,7 & 14,0 & 11,5 & 14,4 \\
Otros & 3,7 & 3,6 & 2,5 & 4,8 & 4,6 & 2,3 & 4,4 & 7,9 & 14,1 & 11,4 & 7,1 & 2,2 & 10,4 & 9,3 & 6,3 \\
\hline
\end{tabular}

Fuente: elaborada por el autor con datos del DNP.

\section{Ingresos tributarios}

En lo correspondiente al esfuerzo fiscal departamental, el indicador en promedio durante el periodo de estudio es de 0,32 evidenciando, en el transcurrir de los años, un comportamiento estable de los ingresos tributarios como proporción de los ingresos totales percibidos por el departamento. Los mejores desempeños del indicador se encuentran en los años 2000 (0.38), 2001 (0.4) y 2013 (0.36) (ver Tabla 4). En valores absolutos, los ingresos producto del ejercicio tributario pasaron en el año 2000 de \$147.012 a \$353.586 millones de pesos en 2013, siendo el año 2011 el de mayor recaudo con $\$ 362.718$ millones de pesos, debido al incremento en el recaudo de otros impuestos (al degüello de ganado, eventos deportivos y similares, venta y premios de loterías); el incremento sostenido en la mayoría de los años se explica por el aumento en la renta percibida por los impuestos a la cerveza, registro y anotación, vehículos y automotores, sobretasa a la gasolina y otros, los cuales presentaron incrementos de 2000 a 2013 de la siguiente manera: cerveza, de \$76.587 a
\$111.577, registro y anotación, de \$10.926 a $\$ 37.662$, vehículos y automotores, de \$12.254 a $\$ 31.693$, y otros, de $\$ 258$ a $\$ 121.952$, datos en millones de pesos.

\section{Carga tributaria per cápita}

La carga tributaria per cápita del departamento de Santander presenta un aumento casi constante durante el periodo de estudio, debido al buen comportamiento del recaudo de los impuestos tributarios. De esta manera, el aporte promedio por habitante, a la entidad territorial, es de $\$ 77.169$ en el año 2000, el cual mostrará una variación negativa del 7,5\% (\$5.760) en el año 2001, debido a la caída del recaudo en los impuestos a la cerveza $(\$ 7.333$ millones) y sobretasa a la gasolina $(\$ 3.763$ millones de pesos); desde este último año hasta el año 2007 se evidencia un crecimiento constante, que en promedio alcanza $11,7 \%$. En cambio, el 2011 constituye el año con mayor carga tributaria per cápita, siendo de \$179.510 millones de pesos, para finalmente en 2013 situarse en $\$ 173.247$ millones de pesos (ver Fig. $3)$. 


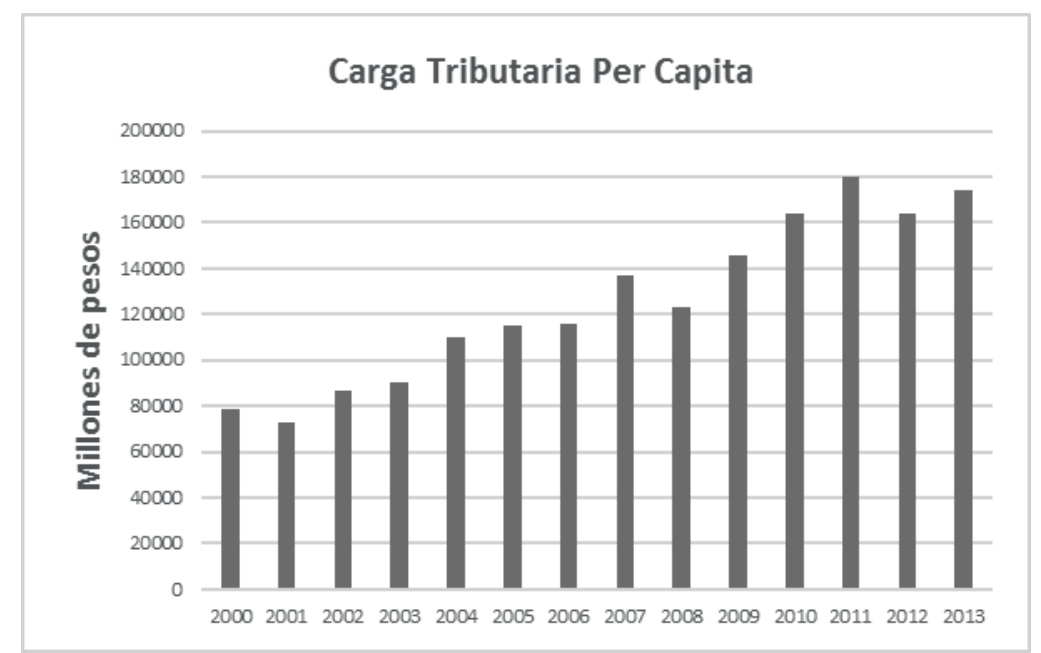

Figura 3. Carga tributaria per cápita

Figure 3. Per capita Tax Load

Fuente: elaborado con datos del DNP.

\section{Ingresos no tributarios}

Los ingresos No tributarios del departamento presentan un comportamiento favorable debido a que los recursos provenientes por tasas, multas, servicios, arrendamientos y rentas de empresas departamentales han mejorado, si bien en los años 2002 y 2003 presentan su peor desempeño aportando a los ingresos corrientes del departamento tan solo $\$ 1.189$ y $\$ 8.062$ millones de pesos, posteriormente en 2004 pasaron a \$20.695 millones de pesos, 2012 se constituye en el año con mayores ingresos, alcanzando la suma de $\$ 35.773$ millones, es decir el 3,6\% de los ingresos totales del departamento (ver tabla 5) siendo las transferencias corrientes el rubro que mayor recauda.

\section{Ingresos de capital}

Los ingresos de capital están compuestos principalmente por las transferencias de la nación vía Sistema General de Participación (SGP) y regalías, representando en el año 2000 \$211.911 millones de pesos, es decir, el 55,4\% de los ingresos totales del departamento para llegar en 2013 a la suma de \$597.275 millones, lo que equivale al $60,8 \%$ de los ingresos totales (ver Tabla 5); los ingresos de capital, durante el periodo 2003-2008, muestran un crecimiento constante que en promedio alcanzan el $12,5 \%$, en 2009 presentan una disminución de $\$ 141.425$ millones respecto al año anterior (2008) lo que repercute directamente en los ingresos totales del departamento (ver Fig. 2), el año de mayor ingreso fue el 2011, por un valor de $\$ 707.451$ millones de pesos.

\section{Transferencias}

Las transferencias, sin duda, se constituyen en componente esencial dentro de los ingresos de capital del departamento, ya que durante el periodo de análisis estos recursos han tenido un comportamiento favorable, pasando de \$114.627 millones de pesos en el año 2000 a $\$ 378.312$ en 2013, siendo el año 2002 el de mayor aporte, con $\$ 492.179$ millones de pesos. En los años 2003 a 2009 los recursos se han mantenido entre $\$ 300.000$ y $\$ 400.000$ millones de pesos. Con lo anterior, el indicador de dependencia intergubernamental muestra un comportamiento favorable, ya que la dependencia de los recursos, que vía SGP percibe el departamento, no es tan alta si estimamos que esta es alta cuando supera el $50 \%$ de los ingresos del ente territorial. Es en los años 2002 y 2003 cuando el indicador de dependencia llega a niveles de 0.68 y 0.54 respectivamente (ver Tabla 5), debido al incrementos de los recursos de transferencias en relación con los incrementos en rubros como los ingresos tributarios y regalías. 


\section{Regalías}

Los ingresos por regalías muestran un comportamiento fluctuante durante el transcurrir de los años, esto debido a la naturaleza en la procedencia de los recursos, siendo el año 2002 el de menor aporte con \$49.875 millones y llegando a su punto más alto en el 2011 con $\$ 216.872$ millones. Las regalías se constituyeron en un factor importante para financiar las políticas de inversión planteadas por las administraciones departamental, y si bien el monto de estos recursos no es estable, dado las variables que la componen (precio dólar, cantidad de barriles producidos), la Ley 1530 de 2012 constituye un desafío, ya que con la entrada en vigencia de la misma los recursos paulatinamente van a disminuir.

El comportamiento del indicador de dependencia intergubernamental, correspondiente a las regalías, evidencia que los recursos por este rubro fluctúan entre el 0,07 y el 0,22 de los recursos totales del departamento (ver Tabla 4), estableciéndose como un buen complemento para la financiación de las políticas establecidas en los planes de desarrollo del departamento y en una fuente de recursos importante para la administración pública.

\section{Los gastos del departamento de Santander}

Los gastos del departamento de Santander para cuestiones contables se encuentran divididos en dos rubros: 1) gastos corrientes, subdivididos en gastos de funcionamiento e intereses y 2) de capital, diseminados en transferencias y formación bruta de capital fijo (FBCF). Los gastos corrientes equivalen al 26,5\% del total de los gastos del departamento, siendo los gastos de funcionamiento donde se direcciona la mayoría de estos recursos. Por su parte, los gastos de capital corresponden al 73,6\% del total de los gastos, de los cuales el 43,9\% corresponde a las transferencias (ver Tabla 6). El comportamiento durante el periodo de estudio evidencia un aumento constante desde el 2003 al 2007, mostrando una caída en el 2008, posteriormente la tendencia alcista se mantiene hasta llegar a su punto más alto en el 2011, $\$ 1.461 .337$ millones (ver Fig. 4) y presentar una disminución en el año 2012 del 41\% respecto al año anterior.

Tabla 6. Composición porcentual de los gastos del departamento de Santander Table 6. Per cent composition of the costs of the department of Santander

\begin{tabular}{|c|c|c|c|c|c|c|c|c|c|c|c|c|c|c|c|}
\hline & 2000 & 2001 & 2002 & 2003 & 2004 & 2005 & 2006 & 2007 & 2008 & 2009 & 2010 & 2011 & 2012 & 2013 & X \\
\hline Total & 100 & 100 & 100 & 100 & 100 & 100 & 100 & 100 & 100 & 100 & 100 & 100 & 100 & 100 & 100 \\
\hline Corrientes & 41,8 & 53,8 & 22,9 & 30,1 & 31,3 & 21,9 & 14,8 & 17,1 & 20,5 & 16,3 & 19,1 & 17,6 & 537,4 & 28,4 & 26,6 \\
\hline Funcionamiento & 36,7 & 50,7 & 16,7 & 24,3 & 27,1 & 19,5 & 12,5 & 15,7 & 19,3 & 16,1 & 18,9 & 17,1 & 36,1 & 27,5 & 24,2 \\
\hline Interés & 5,2 & 3,1 & 6,2 & 5,8 & 4,2 & 2,4 & 2,3 & 1,3 & 1,2 & 0,2 & 0,2 & 0,5 & 1,3 & 0,9 & 2,5 \\
\hline De Capital & 58,2 & 46,2 & 77,1 & 69,9 & 68,7 & 78,1 & 85,2 & 82,9 & 79,5 & 83,7 & 82,4 & 82,4 & 62,6 & 71,6 & 73,5 \\
\hline Transferencias & 58,2 & 46,2 & 77,1 & 7,8 & 56,4 & 55,8 & 37,8 & 34,5 & 37,1 & 46,0 & 33,9 & 35,9 & 7) 43,9 & 40,0 & 43,6 \\
\hline$F B C F$ & 0,0 & 0,0 & 0,0 & 62,2 & 12,3 & 22,3 & 47,5 & 48,5 & 42,4 & 37,7 & 48,5 & 46,5 & 5 18,7 & 31,6 & 29,9 \\
\hline
\end{tabular}




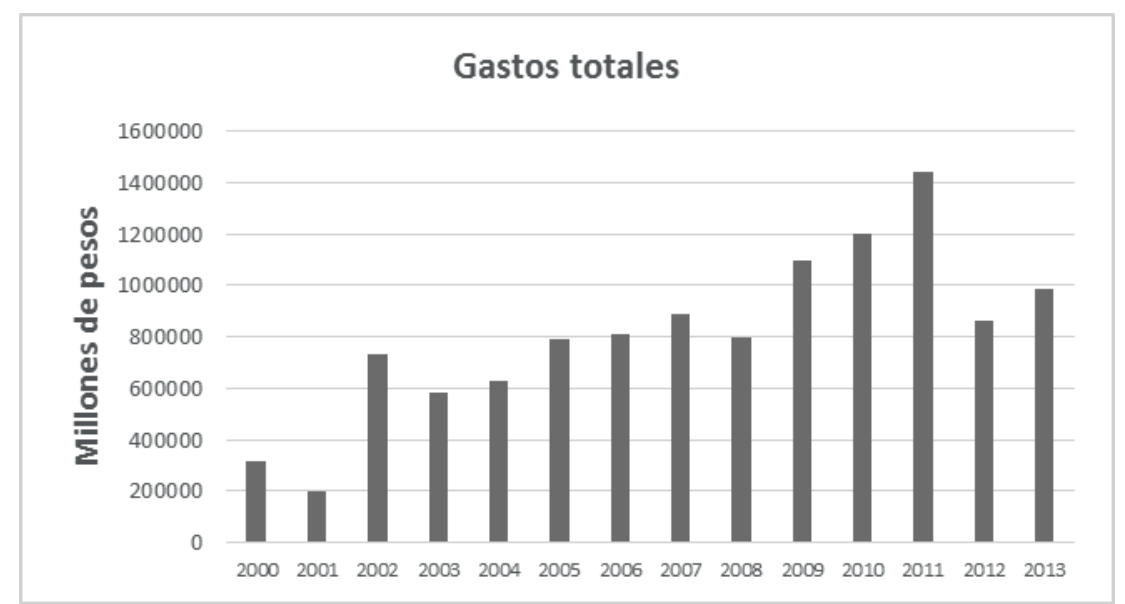

Figura 4. Gastos Totales Departamento de Santander 2000-2013

Figura 4. Total Expenses Department of Santander 2000-2013

Fuente: elaborada con datos del DNP.

\section{Gastos corrientes}

El comportamiento de los gastos corrientes evidencia un aumento considerable, al pasar en el año 2000 de $\$ 135.220$ millones a \$278.655 millones de pesos en 2013, mostrando un aumento sostenido durante los años 2007 a 2012. Este comportamiento se ve influenciado por los gastos de funcionamiento que determinan el direccionamiento de los gastos corrientes; los gastos de funcionamiento presentan un aumento considerable desde el 2007, \$139.936 millones, sosteniendo su incremento hasta el año 2012, \$311.739 millones de pesos, siendo este el año de mayor gasto por ese rubro.

El componente gastos de funcionamiento es un factor importante para determinar la autonomía fiscal con la que cuenta el departamento, es por esto que el comportamiento de este indicador -autonomía fiscal departamental- es la mejor forma para determinar la capacidad del departamento para sostener las actividades propias para el ejercicio de su actividad administrativa, lo que para el caso del departamento de Santander resulta ser aun alto, a pesar de los esfuerzos que la administración departamental ha realizado para recategorizar al departamento, lo cual se logró en el año 2010 (primera categoría), (ver Tabla 4).
Gastos de capital

Los gastos de capital son el gruesos de los gastos totales del departamento representando en el año 2000, \$187.912 millones de pesos, es decir el 58,2\% del total de los gastos del departamento; durante el periodo 2004-2007 el incremento de los gastos es sostenido en promedio del 16,1\%, siendo el año 2011 el que presenta el mayor monto en los gastos de capital, de \$1.203.976 millones de pesos, para presentar en el siguiente año, 2012, una disminución abrupta del 55\% respecto al año anterior, llegando al monto de \$540.812 millones de pesos.

El anterior comportamiento es generado principalmente por los incrementos en el gasto en los sectores de salud, educación y saneamiento básico quienes en promedio durante el periodo de estudio representan el $43.6 \%$ del gasto total del departamento (ver tabla 6), el aumento y disminución del gasto en estos sectores son los determinantes de la fluctuación del gasto de capital.

\section{CONCLUSIONES}

El marco normativo del proceso de descentralización fiscal en Colombia evidencia avances importantes durante el transcurrir de los años, mostrando adaptabilidad a la dinámica 
económica y social que se genera en el país y sus territorialidades, siendo las rentas producto del ejercicio tributario (impuesto a la cerveza, licor, cigarrillos, sobretasa, otros), constituyéndose en la principal herramienta para la autofinanciación de los Gobiernos regionales en pro del cumplimiento de las obligaciones dispuestas por la Ley.

El análisis de los indicadores fiscales de dependencia intergubernamental departamental, autonomía fiscal y esfuerzo fiscal, revelan que la descentralización fiscal en el departamento de Santander encuentra limitantes, como la carencia de autonomía financiera (dependencia de los recursos vía SGP y regalías), la inelasticidad de los impuestos y la sobre posición de impuestos locales, estos dos últimos factores atentan contra un mejor $y$ mayor recaudo tributario.

La situación fiscal del departamento de Santander presenta un problema estructural que puede en el futuro comprometer las finanzas públicas del departamento, debido al incremento promedio de sus ingresos totales en contraposición con el crecimiento de los gastos totales, ya que los primeros aumentaron en promedio durante el periodo de estudio un $10,8 \%$, en donde los dos principales rubros que los componen (los ingresos tributarios y los ingresos corrientes) crecieron en promedio un $7,5 \%$ y $16,6 \%$ respectivamente.

Por otro lado, los gastos totales se elevaron un $21,3 \%$ en promedio, y sus dos principales componentes, formación bruta de capital y gastos de funcionamiento, en un $24,5 \%$ y $8,5 \%$ respectivamente, implicando que la tasa promedio de crecimiento del gasto, durante los años 2000-2013, es casi el doble que el incremento de los ingresos en el mismo periodo, lo que podría generar problemas de financiamiento obligando al departamento a otros tipos de financiación, como sería la deuda pública.

\section{REFERENCIAS}

Aghón, G, Krause-Junk, G. (1993). Descentralización fiscal: Marco conceptual. http://www.cepal.org/publicaciones/xml/6/ 7786/LCL793.pdf

Asela, J. (2014). La descentralización en Colombia, ¿realidad o espejismo? Consideraciones sobre la Actualidad del Proceso. Revista CEA, 1(1), 65-74.

Carrillo, L. (octubre, 2009). Financiación del desarrollo territorial. Seminario Finanzas Públicas Territoriales y Sostenibilidad Fiscal. Bogotá, Colombia.

Constitución Política de Colombia (2012). Bogotá: Legis.

Departamento Administrativo Nacional de Estadística. (2010). Estimación y proyección de población nacional, departamental y municipal total por área 1985-2020. Recuperado de: https://www.dane.gov.co/index.php/poblaci on-y-demografia/proyecciones-depoblacion

Departamento Nacional de Planeación. Ejecuciones presupuestales. de 2014 de: https://www.dnp.gov.co/programas/desarr ollo-territorial/Paginas/ejecucionespresupuestales.aspx

territoriales. de 2014 de:https://www.dnp.gov.co/programas/des arrollo-territorial/Paginas/historico-departicipaciones-territoriales.aspx

Recursos Propios. de: https://www.dnp.gov.co/atencion-alciudadano/glosario/Paginas/R.aspx

Eaton, K. (2004). Designing Subnational Institution: Regional and Municipal Reforms in Postauthoritarian Chile. Comparative Political Studies, 37(2) 218-244. 
Falleti, T. (2005). A Sequential Theory of Decentralization: Latin American Cases in Comparative Perspective. American Political Science Review. 99(3) 327-346.

Finot, I. (2002). Descentralización y participación en América Latina: una mirada desde la economía. Revista de la CEPAL, 78, 139-149.

Junguito, R. y Rincón, H. (agosto, 2004). La Política Fiscal en el Siglo XX en Colombia. Seminario Investigaciones Recientes Sobre Historia Económica Colombiana. Bogotá, Colombia.

Ley 617 de 2000. Por la cual se reforma parcialmente la Ley 136 de 1994, el Decreto extraordinario 1222 de 1986, se adiciona la
Ley Orgánica de Presupuesto, el Decreto 1421 de 1993, se dicta otras normas tendientes a fortalecer la descentralización, y se dictan normas para la racionalización del gasto público nacional.

Ley 1551 de 2012. Por la cual se dictan normas para modernizar la organización y el funcionamiento de los municipios.

Penning, J. (2003). Evolución del Proceso de Descentralización en Colombia. Economía y Desarrollo, 2(1), 123-149.

Wiesner, E. (2002). Transferencias, incentivos y la endogeneidad del gasto territorial. Archivos de Economía, Departamento Nacional de Planeación, Documento 174, Bogotá. 